\title{
Esquistossomose endocervical
}

\author{
Endocervical schistosomiasis
}

\author{
Giovana Bachega Badiale', Daniel Ferraciolli Brandão \\ e Alfredo Ribeiro-Silva ${ }^{1}$
}

\begin{abstract}
RESUM0
Relatamos o caso de uma mulher de 38 anos, assintomática, que procurou atendimento médico devido à infertilidade. No exame ginecológico, observou-se pólipo endocervical de 1,0 × 0,8 × 0,5cm que foi biopsiado. 0 exame histológico evidenciou granulomas contendo ovos de Schistosoma mansoni.
\end{abstract}

Palavras-chaves: Esquistossomose. Colo uterino. Pólipo endocervical.

\begin{abstract}
We report the case of an asymptomatic 38-year-old woman that sought medical assistance due to infertility. The gynecological examination showed an endocervical polyp measuring 1.0 x 0.8 x $0.5 \mathrm{~cm}$. A biopsy was performed. Under microscopy, several granulomas containing eggs of Schistosoma mansoni were seen.
\end{abstract}

Key-words: Schistosomiasis. Uterine cervix. Endocervical polyp.

As principais localizações do corpo humano acometidas pela esquistossomose são 0 fígado e 0 intestino, onde se desenvolvem granulomas contendo no seu interior ovos do esquistossomo $0^{8} .0$ trato genital feminino também pode ser envolvido, havendo relatos de acometimento da cérvice, ovário, clitóris e tuba uterina ${ }^{1}$.

\section{RELATO DE CASO}

Uma mulher de 38 anos, que teve três gestações com um parto normal, duas cesáreas e nenhum aborto, fez laqueadura tubárea há quinze anos. Pelo desejo de ter novos filhos, procurou assistência médica para realização de reprodução assistida. A paciente não apresentava queixas ginecológicas e negou qualquer história de moléstias anteriores. Ao exame físico geral, não se evidenciaram anormalidades e ao exame especular e colposcópico foi visualizada uma estrutura polipóide na região endocervical que foi ressecada e enviada para exame anátomopatológico. Além disso, foram colhidos esfregaços endocervicais para cultura, que resultaram negativos, e esfregaços vaginal, cervical e endocervical para avaliação citológica, que não exibiram alterações.
Macroscopicamente, a estrutura polipóide endocervical era constituída por um fragmento irregular de tecido pardo e firme medindo $1,0 \times 0,8 \times 0,5 \mathrm{~cm}$, que foi totalmente incluído para análise histopatológica. À microscopia, os cortes histológicos exibiam exuberante processo inflamatório misto, com áreas de granulomas com ocasionais células gigantes multinucleadas. Foram observadas numerosas estruturas morfologicamente compatíveis com Schistosoma mansoni ( Figura 1).

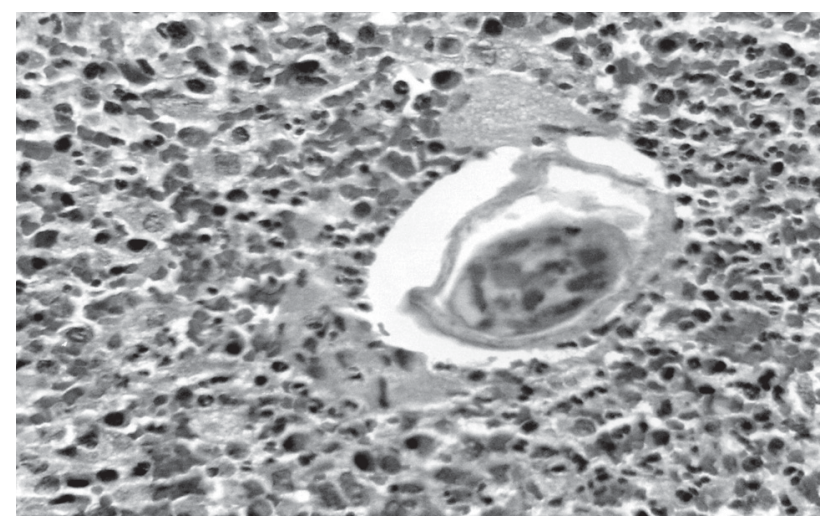

Figura 1 - 0vo de Schistosoma mansoni em meio a exuberante infiltrado inflamatório misto (hematoxilina e eosina, $\mathrm{x} 400$ ).

1. Departamento de Patologia da Faculdade de Medicina de Ribeirão Preto da Universidade de São Paulo, Ribeirão Preto, SP.

Endereço para correspondência: Dr. Alfredo Ribeiro-Silva. Depto de Patologia/FMRP/USP. Av. Bandeirantes 3900, Campus Universitário, Monte Alegre, 14048-900 Ribeirão Preto, SP, Brasil

Tel: + 5516 602-3244; Fax: + 5516 633-1068

e-mail: arsilva@fmrp.usp.br

Recebido para publicação em 7/4/2004

Aceito em 2/5/2005 


\section{DISCUSSÃ0}

Aesquistossomose cervical émais comum em mulheresinfectadas com Schistosoma haematobium, com freqüência variando de $33 \%$ a $75 \%{ }^{56}$. Ainfecção do trato genital feminino pelo S. mansoni é muito mais rara. Ovos do parasita são encontrados no colo uterino em 4 (0,3\%) de 1.250 mulheres infectadas pelo S. mansoni ${ }^{2,4}$.

Clinicamente, 0 acometimento do trato genital feminino pelo esquistosomo geralmente é assintomático, e os ovos são descobertos em exames rotineiros 6 . Entretanto, podem ocorrer sangramentos pós-coital, intermenstrual e pós-menstrual, infertilidade, corrimento vaginal e dismenorréia. Esses sintomas não são conseqüências diretas da esquistossomose, mas sim de uma cervicite secundária, que geralmente está associada a esses casos $^{7}$. No presente relato, a paciente era assintomática, visto que sua infertilidade era decorrente de laqueadura tubárea prévia.

Ao exame colposcópico, o colo pode exibir hipertrofia nodular, lesões polipóides, úlceras, erosões e lesões de aspecto arenoso $0^{6}$. 0 diagnóstico pode ser feito através da pesquisa de ovos em esfregaços vaginais rotineiros ou através do exame histológico feito em amostras provenientes de biópsia ${ }^{1}$.

Existe controvérsia se a esquistossomose está associada ao desenvolvimento de carcinoma do colo uterino. Coelho e cols encontraram carcinoma em 3 de 1.250 amostras de biópsia de colo provenientes de pacientes com esquistossomose, sugerindo uma associação entre essas patologias ${ }^{2}$. Esses dados, entretanto, foram posteriormente refutados por outros autores que alegaram que 0 carcinoma verificado nesses casos foi decorrente da co-infecção pelo papiloma vírus humano, e não pelo esquistossomo per se ${ }^{7}$.
0 tratamento é feito com oxamniquine, na dose única de $15 \mathrm{mg} / \mathrm{kg}$. Como segunda escolha, tem-se o praziquantel, na dose única de $50 \mathrm{mg} / \mathrm{kg}$, via oral, para adultos ${ }^{3}$. 0 tratamento com uma dessas drogas é suficiente para reverter as lesões cervicais, não sendo necessária a excisão cirúrgica das mesmas ${ }^{1}$.

\section{REFERÊNCIAS BIBLIOGRÁFICAS}

1. Adeniran A, Dimashkieh H, Nikiforov Y. Schistosomiasis of the cervix. Archives of Pathology \& Laboratory Medicine 127:1637-1638, 2003.

2. Coelho LH, Carvalho G, Carvalho JM. Carcinoma in situ and invasive squamous cell carcinoma associated with schistosomiasis of the uterine cervix a report of three cases. Acta Cytologica 23:45-48, 1979.

3. Croft SL, Vivas L, Brooker S. Recent advances in research and control of malaria, leishmaniasis, trypanosomiasis and schistosomiasis. East Mediterranean Health Journal 9:518-533, 2003.

4. File S, Francheschini AB, Fernandez-Santiago A. A case of ectopic schistosomiasis in Puerto Rico with some observations on the biology of the parasite. American Journal of Tropical Medicine and Hygiene 58:671-672, 1998

5. Poggensee G, Krantz I, Kiwelu I, Diedrich T, Feldmeier H. Presence of Schistosoma mansoni eggs in the cervix uteri of women in Mwanga District, Tanzania. Transactions of the Royal Society of Tropical Medicine and Hygiene 95:299-300, 2001.

6. Poggensee G, Sahebali S, Van Marck E, Swai B, Krantz I, Feldmeier H. Diagnosis of genital cervical schistosomiasis: comparison of cytological, histopathological and parasitological examination. The American Journal of Tropical Medicine and Hygiene 65:233-236, 2001.

7. Rand RJ, Lowe JW. Schistosomiasis of the uterine cervix. British Journal of Obstetrics \& Gynecology 105:1329-1331, 1998.

8. Silva LC, Chieffi PP, Carrilho FJ. Schistosomiasis mansoni: clinical features. Gastroenterologia y Hepatologia 28:30-39, 2005. 